\title{
Posterior longitudinal ligament resection during microscopic anterior cervical discectomy: technique and safety consideration
}

\author{
Ashraf Mohamed Farid*io and Sherif Elsayed ElKheshin
}

\begin{abstract}
Background: Herniation of the cervical disk material results in interruption of the posterior longitudinal ligament (PLL) in the majority of patients. Routine opening of the PLL during ACDF is a necessary step for complete removal of all disk fragments.

Objectives: Safety measures during PLL opening during microscopic anterior cervical discectomy and risk-free surgery

Study design: A retrospective clinical case series

Patients and methods: The study was conducted on 145 patients. The main symptom was radicular pain. Preoperative identification of PLL was assessed by MRI. All patients were operated upon by ACDF. We started dissection off the midline in patients with intact ligament while we used the site of disruption to start and complete dissection in patients with interrupted ligament. Follow-up was done monthly.

Results: Ninety-seven percent of patients underwent single level surgery. The most commonly operated level was C5-6. PLL was interrupted in $60.7 \%$ of patients. There was a statistically significant difference between median VAS in immediate, early, and late post-operative period. Bleeding was encountered in $46 \%$ of patients. Saline irrigation was a suitable method for hemostasis.

Conclusion: Conventional MRI is the modality of choice for pre-operative identification of PLL. It is better to use the site of ligament interruption to start sharp dissection and to start lateral to the midline in intact ligament. Sharp dissection is better with curved knife. Thin foot plate Kerrison is suitable for excision of the remaining parts. Hemostasis using saline irrigation is better and non-risky than using bipolar coagulation.
\end{abstract}

Keywords: Posterior longitudinal ligament dissection, Safety measures

\section{Introduction}

Cervical disk herniation results from a tear in the posterior annulus and the posterior longitudinal ligament (PLL). Consequently, there is a sequestrated disk fragment inside the spinal canal causing cord and/or root compression [1].

During microscopic anterior cervical discectomy with fusion (ACDF), violation of the PLL aiming at dural exposure and subligamentous disk fragment removal is

\footnotetext{
* Correspondence: Aschraffarid@gmail.com

Neurosurgery Department, Tanta University, Tanta, Egypt
}

indispensable surgical step to ensure complete removal. The structural integrity of the PLL broadens at the level of the disk through incorporation with the posterior annulus onto its thick deep layer. It has also a thin superficial layer that is related to the dura matter [2-4]. The superficial and deep layers are separate laterally while adherent in the mid-line. Fibers are running as a band in the mid-line but are dispersed laterally $[5,6]$.

The extradural veins are anastomosed beneath the PLL. The contribution with the internal veins forms a confluence at the intervertebral foramen. The nerve roots, as they leave the intervertebral foramen, have 
accompanying veins that receive contribution ventral radicular veins, which pierce the dura $[7,8]$. The venous plexus lies between the two layers of PLL $[9,10]$.

The advantage of PLL dissection requires not to overlook its intimate relation to the dural sac to avoid a troublesome unintended durotomy or bleeding. Safety considerations aim at risk-free surgery which are the core of this study.

\section{Patients and methods}

\section{Patient population}

This is a retrospective clinical case series conducted on 74 males and 71 females (total=145) in the Department of Neurosurgery, Tanta University Hospitals. Those patients were operated upon for anterior cervical discectomy and fusion in the period between December, 2016, and February, 2019. The main symptoms were radicular pain $(73.8 \%)$ (measured by visual analog scale), motor weakness (47.6\%), radicular hypoesthesia (39.3\%), myelopathic symptoms (29.7\%), diminished reflexes (19.3\%), and lastly, interscapular pain (6.2\%) (Table 1). All patient's data, diagnosis, and treatment outcomes are confidentially kept private and patients had specific codes. An informed consent for surgery was taken from all patients [11]. An approval from the research ethics committee of the Faculty of Medicine, Tanta University [reference number 33038], was obtained on April, 2019. Furthermore, being a retrospective study, patients' consents for participation and for publication were not applicable. Additionally, the co-authors had neither financial nor non-financial competing interest to report.

\section{Imaging}

MRI was the main imaging modality. Sagittal and axial $\mathrm{T} 1$ and T2 were done for evaluation of the protruded disk material and integrity of the PLL $[12,13]$. PLL was interrupted in 88 patients (Fig. 1a, b) and intact in 57 patients (Fig. 1c, d) (total=145). Neither of those patients who had radicular pain improved after a trial of nonsurgical treatment. C5-6 was the most common level operated upon (53\%) followed by C4-5 in 22\%, C6-7 in $15 \%$, and lastly, C3-4 in 10\% of patients (Table 2).

\section{Surgical procedures \\ Position}

The patient was put in a supine position. In patients with myelopathic picture, we took the precaution of awake positioning to avoid direct cord compression at the time interval between the start of anesthesia and the proper surgical resection. A rounded roll was put between the patient scapulae in the mid-line. An intraoperative image was initially taken for localization of the desired level and the proper site of skin incision.

\section{Anesthetic considerations}

With communication with the anesthesiology team, considerations executed by avoidance of neck extension through insertion of the endotracheal tube via the fiberoptic techniques and use of a low-pressure cuff with inflation of air below the maximum volume that is labeled on the cuff, thus avoidance of the risk of compression on the recurrent laryngeal nerve. In addition, we also recommended insertion of the cuff below the level of the vocal cord [14].

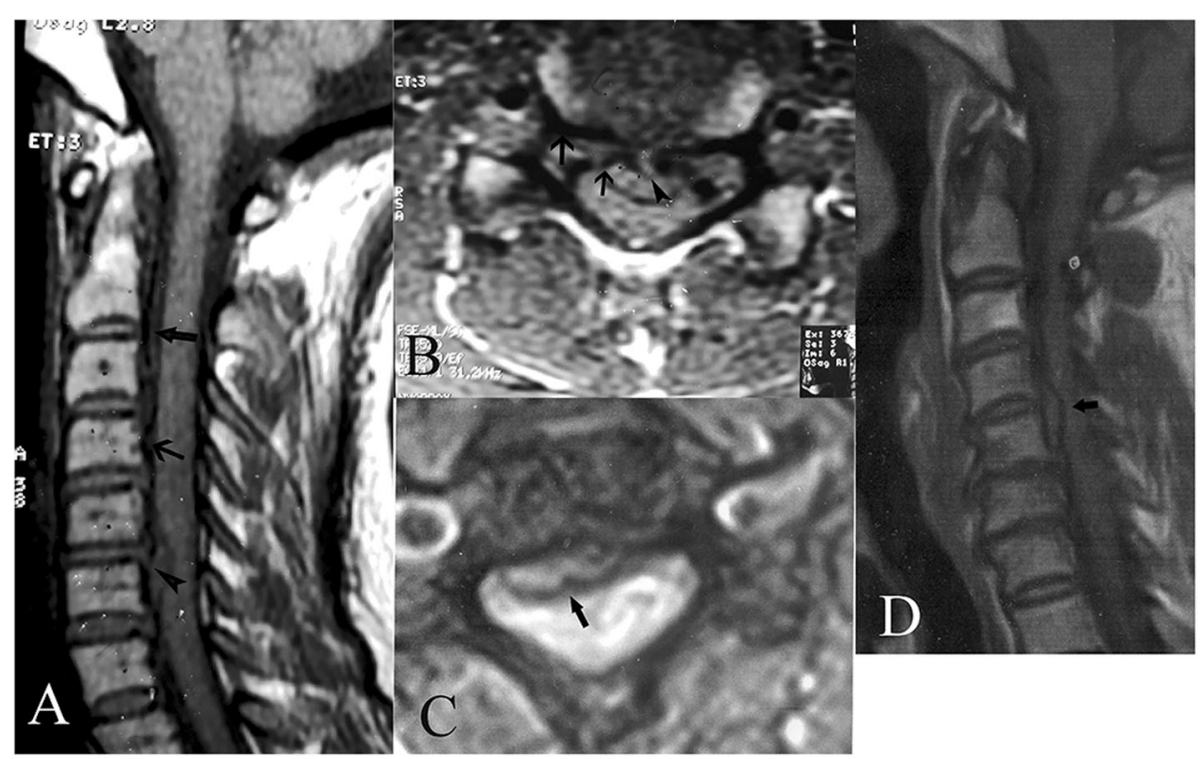

Fig. 1 a, b Sagittal and axial T1 MRI cervical spine. Arrows point to an intact PLL. The arrowhead points to the site of PLL interruption through which the disk material herniates. c, d Axial and sagittal MRI cervical spine; black arrows point to an intact PLL 


\section{Surgical technique}

A transverse skin crease incision was done followed by platysma muscle incision. Identification of the sternocleidomastoid muscle was done to work just medial to it. Blunt dissection of the investing layer of deep cervical fascia was done. Care was taken to keep the carotid sheath intact. The plane between the carotid sheath laterally and trachea and esophagus medially was gently dissected till reaching the anterior aspect of the cervical spine.

Identification of the planned level was done by intraoperative imaging. The operating microscope was finally introduced. Under magnification, the longus colli muscles were separated using bipolar cauterization. Following resection of the anterior annulus and central disk material and using the back of micro-tumor knife, a peculiar resection of the cartilaginous end plates above and below created an additional space and obviated the need to marked Caspar distraction which switches the strands of PLL, bringing it more intimate to dura. The magnification power was increased at this step to identify the posterior annulus and the PLL.

Careful inspection of the ligament was done with assessment of its integrity according to the pre-operative MRI evaluation. In patients with intact ligament, we started dissection laterally using sickle knife and rightangled blunt microhook which was rotated between two strands of the ligament until the ligament is lifted up away from the dura and then sharply cut with a knife. Once divided, a continued lifting up of the ligament and further resection is carried out by a sickle knife or thin foot plate 1 and $2 \mathrm{~mm}$ Kerrison and without traction until the dura is bare (Fig. 2). This dissection is continued on one side only in cases of posterolateral herniation to the confines of uncovertebral joint. The blunt micro hook could be then rotated underneath the uncovertebral joint to bring up far lateral fragments. In patients, in whom there was ruptured disk material through a tear in the PLL and the dura was clearly visualized after excision of the ruptured disk fragment, we completed the PLL dissection beginning from that tear towards both sides (Fig. 3). Finally, adequate hemostasis was done. Finally, the interbody hardware was inserted under intraoperative image guidance.

Great cautions were taken near and beneath the uncovertebral joint where the exit of the root and the surrounding veins. When there was venous bleeding, irrigation with saline under gentle pressure was done. In spite of spending some time, it was a successful maneuver to stop that bleeding [15].

\section{Post-operative care and follow-up}

Assessment of the motor power was routinely done. Postoperative evaluation of pain was done using the visual analog scale and compared with the preoperative record. Early post-operative pain was considered at the 1 st $48 \mathrm{~h}$ after surgery while late post-operative pain was considered a week post-operatively. After discharge, regular monthly follow-up visits were planned with the patient (Fig. 4).

\section{Statistical analyses}

Analysis was done using IBM SPSS ${ }^{\circ}$ statistics for windows.

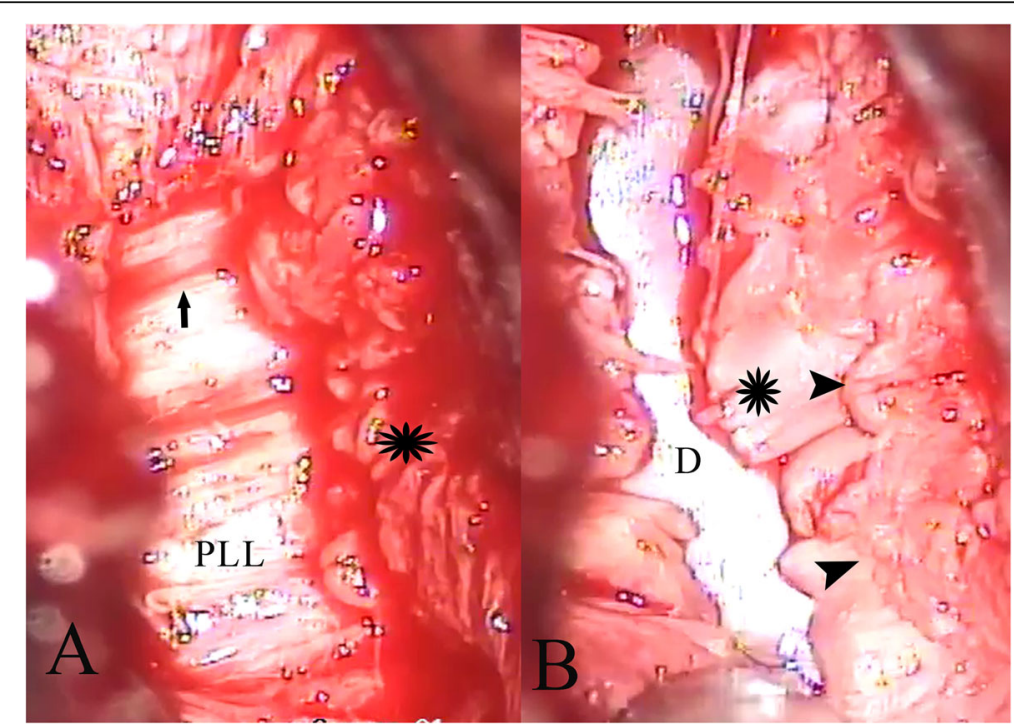

Fig. 2 a Operative view showing an intact PLL. Arrow points to the site of microhook entry to dissect. The asterisk refers to the posterior annulus. b After opening the PLL. D dura, the asterisk refers to the edges of PLL, and the arrowhead points to the annulus 


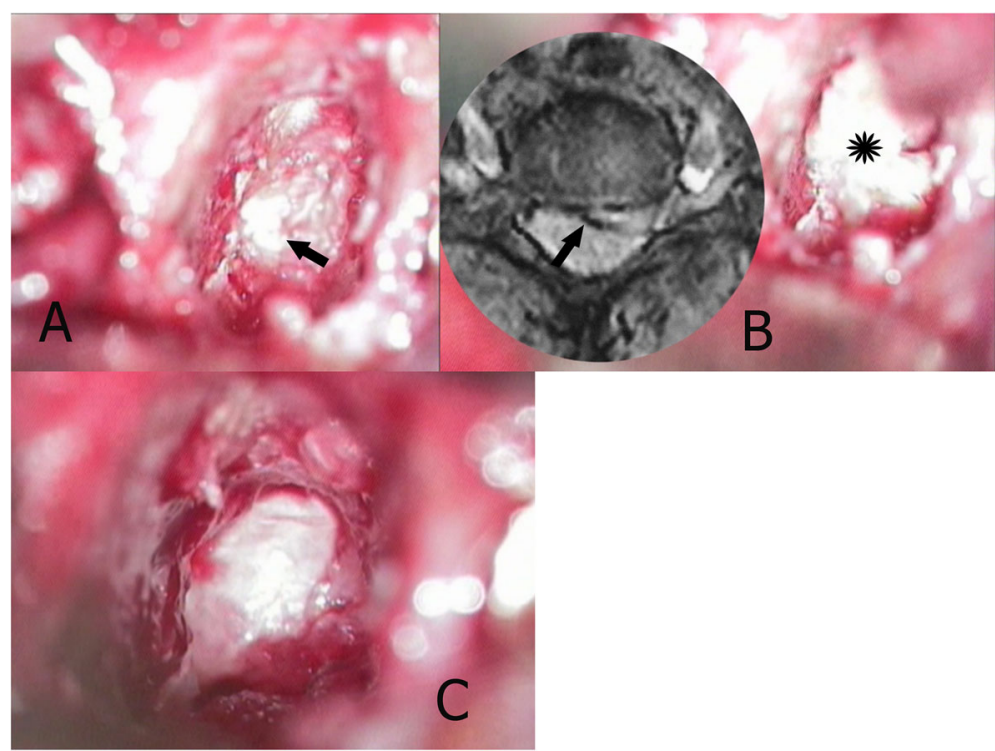

Fig. 3 a Operative view; arrow points to a disk fragment. b Axial T1 MRI superimposed on the operative photo showing ruptured PLL (arrow) and posterolateral herniated disk fragment. The asterisk refers to the extracted disc fragment leaving a defect in PLL. c Complete opening of PLL

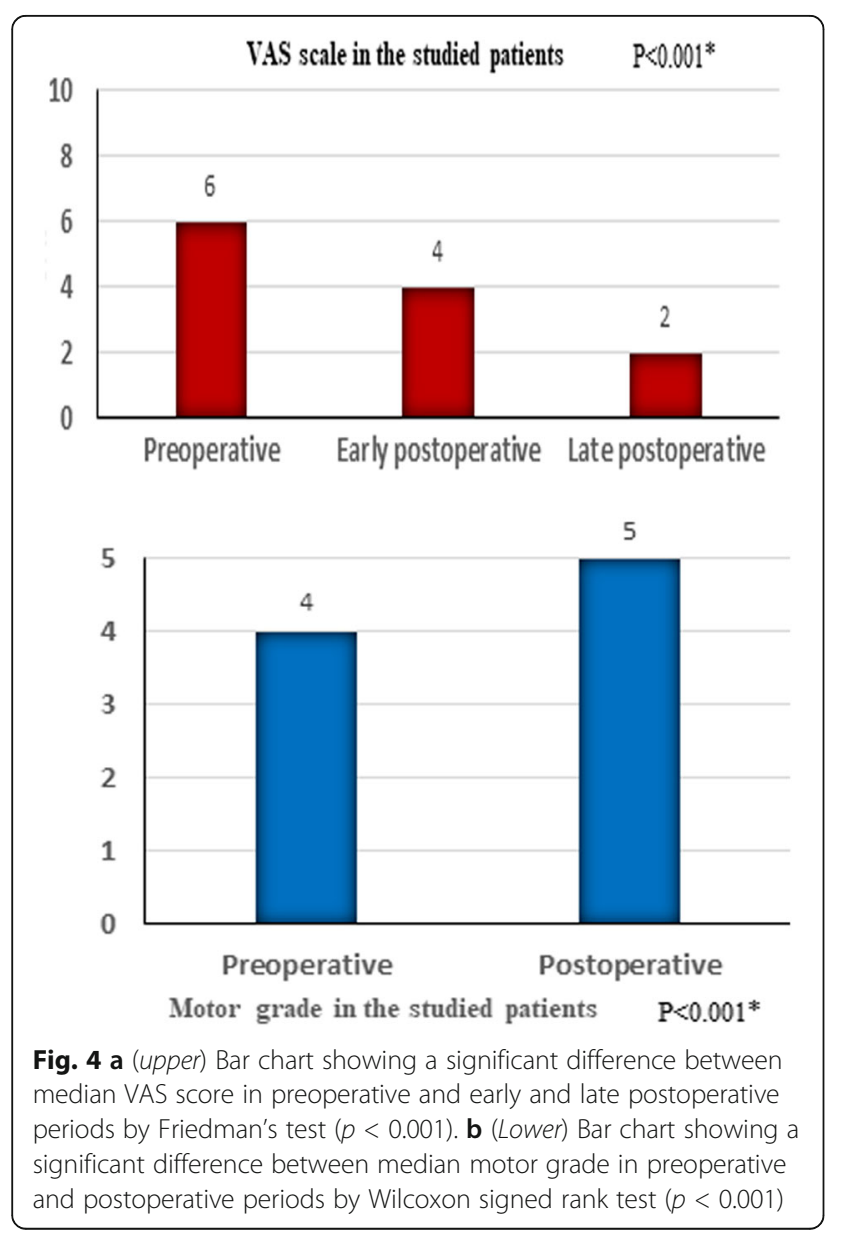

\section{Results}

Table 1 summarizes the sociodemographic data and the preoperative manifestations of the studied patients. This study was carried out on 145 patients whose age ranged from 25 to 77 years old, with an average of $44 \pm 10$ years. Men accounted for $51 \%$ of the studied sample. The commonest presenting manifestation was radicular pain $(73.8 \%)$, followed by motor weakness $(47.6 \%)$, radicular hyperesthesia (39.3\%), myelopathy (29.7\%), and diminished reflexes (19.3\%), and the least was

Table 1 Characteristics of the studied patients who underwent anterior cervical discectomy and fusion $(n=145)$

\begin{tabular}{llll}
\hline & & \multicolumn{2}{l}{ All patients } \\
\hline Age & Min-Max & $25-77$ & \\
& Mean \pm SD & $44 \pm 10$ & \\
Gender & Female & 71 & $49.0 \%$ \\
& Male & 74 & $51.0 \%$ \\
Preoperative manifestations & Radicular pain & 107 & $73.8 \%$ \\
& Motor weakness & 69 & 47.6 \\
& Radicular hyperesthesia & 57 & $39.3 \%$ \\
& Myelopathy & 43 & $29.7 \%$ \\
& Diminished reflexes & 28 & $19.3 \%$ \\
& Interscapular pain & 9 & $6.2 \%$ \\
Preoperative VAS & Min-Max & $0-9$ & \\
Preoperative motor grade & Median (IQR) & $6(2-7)$ & \\
& Min-Max & $0-5$ & \\
& Median (IQR) & $4(3-5)$ & \\
\hline
\end{tabular}

IQR interquartile range, Min minimum, Max maximum, SD standard deviation, VAS visual analog scale 
interscapular pain (6.2\%). The median VAS score was 6, with interquartile range (IQR) $2-7$ (50\% of patients had VAS between 2 and 7). The median motor grade was 4 , with IQR 3-5 (50\% of patients had motor grade between 3 and 5).

Table 2 shows the operative details of the patients and their condition after surgery. The time from the diagnosis until surgery was performed ranged between less than a day to 36 days, with a median of 4 days and IQR 3-6 days. The majority of patients (97.2\%) underwent surgery at a single level, while only four patients $(2.8 \%)$ underwent surgery at two levels. Slightly more than half of the patients (53.1\%) had surgery at the level of C5-C6, while the least frequency was at the level of C3-C4 (14 patients, 9.7\%). The posterior longitudinal ligament (PLL) appeared interrupted in MRI in $60.7 \%$ of patients. During surgery, subligamentous radicular disk fragments were found in $41.4 \%$ of patients, while in $39.3 \%$ of cases, no subligamentous fragments were found. The commonest intraoperative event was bleeding (46\%). The postoperative degree of pain as measured by VAS score had a median of 4 (IQR 0-4), but decreased later to a median of 2 (IQR $0-2$ ). The postoperative motor grade had a median of 5 . Figure $4 \mathrm{a}$ demonstrates that the median
VAS score in preoperative had significantly decreased in early postoperative period, then decreased significantly also in late postoperative period (Friedman's test was performed followed by pairwise comparisons, $(p<$ 0.001 ). Figure $4 \mathrm{~b}$ shows a significant increase in motor grade postoperatively compared with the preoperative grade (Wilcoxon signed rank test, $p<0.001$ ).

\section{Discussion}

Safety considerations and risk-free surgery were the core of this study. Our study included $9.7 \%$ of patients had C3-4 disk, 22\% had C4-5 disk, 53.1\% had C5-6 disk (the most common), and $15.2 \%$ had C6-7 disk. Kienapfel et al. [16] reported also that the most commonly affected levels were C5-6 and C4-5.

In our study, we depended upon MRI for assessment of PLL pre-operatively, which was interrupted in $60.7 \%$ while it was intact in 39.3\%. Takhtani and Melhem [17] demonstrated the sensitivity of MRI to assess PLL interruption in both sagittal T1 and T2. It is hypointense in both T1 and T2. PLL is usually interrupted by the ruptured disk fragment. Moreover, Yamazaki et al. [18] reported that disk herniation usually induces tears in both the superficial and deep layers. Consequently, there is

Table 2 Operative details, complications, and degree of pain and motor grade $(n=145)$

\begin{tabular}{|c|c|c|c|}
\hline & & All patients (145) & \\
\hline \multirow[t]{2}{*}{ Timing till surgery (days) } & Min-Max & $<24 \mathrm{~h}-36$ & \\
\hline & Median (IQR) & $4(3-6)$ & \\
\hline \multirow[t]{6}{*}{ Level of surgery } & One level & 141 & $97.2 \%$ \\
\hline & Two levels & 4 & $2.8 \%$ \\
\hline & $\mathrm{C} 3-\mathrm{C} 4$ & 14 & $9.7 \%$ \\
\hline & $\mathrm{C} 4-\mathrm{C} 5$ & 32 & $22.8 \%$ \\
\hline & C5-C6 & 77 & $53.1 \%$ \\
\hline & $\mathrm{C} 6-\mathrm{C} 7$ & 22 & $15.2 \%$ \\
\hline \multirow[t]{2}{*}{ PLL in MRI } & Interrupted & 88 & $60.7 \%$ \\
\hline & Stretched & 57 & $39.3 \%$ \\
\hline \multirow[t]{4}{*}{ location of disk fragments } & No subligamentous fragment & 57 & $39.3 \%$ \\
\hline & Subligamentous central & 21 & $14.5 \%$ \\
\hline & Subligamentous central and lateral & 7 & $4.8 \%$ \\
\hline & Subligamentous lateral & 60 & $41.4 \%$ \\
\hline \multirow[t]{2}{*}{ Intra-operative events } & Bleeding from vascular cuff around root & 67 & $46.2 \%$ \\
\hline & Incidental durotomy & 1 & $0.7 \%$ \\
\hline \multirow[t]{2}{*}{ Postoperative VAS (early) } & Min-Max & $0-6$ & \\
\hline & Median (IQR) & $4(0-4)$ & \\
\hline \multirow[t]{2}{*}{ Postoperative VAS (late) } & Min-Max & $0-3$ & \\
\hline & Median (IQR) & $2(0-2)$ & \\
\hline \multirow[t]{2}{*}{ Postoperative motor grade } & Min-Max & $0-5$ & \\
\hline & Median (IQR) & $5(5-5)$ & \\
\hline
\end{tabular}

IQR interquartile range, Min minimum, Max maximum, SD standard deviation, PLL posterior longitudinal ligament, VAS visual analog scale 
fibrous tissue reaction and vascular proliferation. So, cautions should be taken during dissection of the ligament. Heary et al. [19] reported that pre-operative MRI may eliminate the need to open PLL provided that it is of high resolution and in T1 and there's continuous PLL.

In our study, we found that PLL is interrupted in $60.1 \%$ (Table 2). Interruption of PLL was recognized intraoperatively after introduction of the operating microscope using its high magnification power. The ligament was known by its longitudinal yellowish fibers. We found that the ruptured disk fragment induced a tear through which it penetrated through the epidural space. By rightangled blunt microhook, we completed sharp dissection of the remaining parts of the ligament on both sides, irrespective of the site of the tear whether central or lateral. We used the right-angled blunt hook to explore beneath the PLL, then completing excision by thin foot plate 1- and 2-mm Kerrison (Fig. 3). Sonntag et al. [20] depended upon micro-curettes and bipolar coagulation, then completing the excision using $1 \mathrm{~mm}$ Kerrison. Our opinion is that 1- and 2-mm thin foot plate Kerrison has the advantages of being not only non-traumatic through its thin foot plate but also sharp in cutting the ligament in situ without traction.

Tu et al. [21] and Terry and Michael [1] recommended routine removal of PLL, so as to be sure that no residual disk material is left behind. On the other hand, Cloward [22] did not recommend the routine removal of PLL due to its protecting effect on the dura matter in addition to the fact that the herniation of posterolateral disk is beyond the lateral border of PLL and the central disk usually herniated through a tear in the PLL. On the other hand, Shapiro [23] reported that it is possible to find calcification of PLL. In such situation, it is advised to leave an island of the ligament adherent. Charles et al. [24] had an opinion that recommends partial removal to protect the dura unless the disk fragment is large. Scott et al. [25] stated that the PLL must be elevated laterally using right-angled blunt microhook and then excised with a thin footplate Kerrison. Precautions should be carried out during resection because of being thin and weak.

In our work, we were convenient with the opinion of routine removal based upon the study of Yamazaki et al. [26] who found an interruption of PLL in all of their patients intraoperatively. In patients with an intact PLL, we started dissection at its lateral border, based upon the anatomical features of the fiber orientation $[5,6,22]$. Optimum Casper distraction was not applied except after adequate visualization of the dura so that the dura is not in direct contact with the PLL.

In our study, bleeding was more common with those patients in whom PLL was resected and had no pre- operative radiologic signs of interruption in MRI. Bleeding near the root exit was encountered in $46 \%$ of our patients (Table 2). We tried to stop it using saline irrigation with a fine irrigation cannula. Okada et al. [15] supported this maneuver. Moreover, Ohyama et al. [27] reported that saline irrigation also minimizes the risk of root due to bipolar cauterization which if necessary, the bipolar forceps must be perpendicular to the root. We did not try to use bipolar coagulation. The only disadvantage of saline irrigation in our work was an additional operative time because using saline needed some patience to stop bleeding.

Weinstein [28] advocated that when venous bleeding occurs, it is possible to debride the PLL of adherent or thickened calcified material and could be left intact. They also recommended cautious coagulation of bleeding coming from the epidural venules or putting a hemostatic agent and augmented with a small piece of cottonoid. On the other hand, he did not recommend bone wax because it prevents fusion. In our work, we used the hemostatic agent after the effect of saline irrigation and a temporary small piece of cottonoid. At the same time, we prepared the hardware for fusion. Thus, exploiting this time for complete hemostasis.

Bertalanaffy and Eggert [29] reported postoperative cervical spinal extradural hematoma following ACDF. They attributed the source of bleeding to the arterial supply of PLL. They advised cauterization of the edges of the PLL. They partially resected the PLL in the majority of their series. Sang and Wilson [30] reported that extradural hemorrhage could result after ACD, and they attributed it to the injury of the arterial arcade. They concluded that the avoidance might be through partial resection and coagulation of the edges. Protzman et al. [31] reported that extradural hematoma could complicate ACDF. They attributed it to local trauma at the operative site and hypertension. Moreover, remote subdural hemorrhage to the thoracic spine was attributable to propulsion of the blood.

In our work, we had only one patient with intraoperative incidental durotomy (Table 2). We put a small piece of graft and no post-operative sequalae. Lin et al. [32] reported one patient with CSF leak. Gabriele et al. [33] reported spinal cord injury, CSF leak after dural injury, and meningitis in addition to nerve root injury. Our opinion is that the sharp dissection of the PLL might be risky with the straight knife because its blade is directed downwards to the dura. On the other hand, the curved knife may be less risky than the straight one because its blade is directed slightly upwards, so it may dissect through the potential space between the dura and PLL. Also avoiding Casper distraction initially may minimize the direct contact of the PLL with the dura. Moreover, starting at the lateral border is better than mid-line. 
In our work, the postoperative degree of pain as measured by VAS score had a median of 4 (IQR 0-4), but decreased later to a median of 2 (IQR 0-2). The postoperative motor grade had a median of 5 . The median VAS score for pain in preoperative had significantly decreased in early postoperative period, then decreased significantly also in late postoperative period (Friedman's test was performed followed by pairwise comparisons, $(p<$ 0.001 ). Figure $4 \mathrm{~b}$ shows a significant increase in motor grade postoperatively compared with the preoperative grade (Wilcoxon signed rank test, $p<0.001$ ). Elayouty et al. [34] had similar results. Lin et al. [32] pointed out that the excision of the PLL may help improve axial neck pain, where they defined axial neck pain as pain which included both nuchal, periscapular, and shoulder regions and its source is debatable. Lin et al. [32] postulated that PLL and the disk may be a source of axial pain, and therefore, PLL resection may help improve axial neck pain. On the other hand, Kienapfel et al. [16] reported that $24 \%$ of their patients had pain, $17 \%$ showed no improvement of radicular pain, and 19\% were dependent upon medications. They reported motor weakness in $17 \%$ of their patients and $11 \%$ had myelopathic features.

It is to be mentioned that Nassr et al. [35] reported that the risk of post-operative C5 palsy after resection of PLL was dependent upon tethering of the nerve by the retropulsed disk fragment and non-cautious manipulation during resection of PLL. They recommended the use of intra-operative monitoring. In our work, we used thin footplate Kerrison and cut the ligament without traction, and also, we separated cautiously the disk fragment using microhook and under high magnification. This was planned to any disk level to avoid incidental durotomy or injury to the venous plexus around the root and also to minimize the risk of root injury. Accordingly, we did not catch such complication.

\section{Conclusion}

Conventional MRI is the modality of choice for preoperative identification of PLL. It is better to use the site of ligament interruption to start sharp dissection and to start lateral to the midline in intact ligament. Right angled blunt microhook is suitable to separate the longitudinal strands of the PLL using high magnification then to start sharp dissection using curved knife. Both 1- and 2-mm thin foot plate Kerrison is suitable for excision of the remaining parts without traction. Routine removal is the optimum for adequacy of disk removal and improvement of pre-operative symptoms. Hemostasis using saline irrigation is better and non-risky than using bipolar coagulation.

\section{Abbreviations}

MRI: Magnetic resonance imaging; PLL: Posterior longitudinal ligament; VAS: Visual analog scale

\section{Acknowledgements}

The authors sincerely thank El-Mahalawy $\mathrm{M}$ and all of the department members of Neurosurgery, Tanta University Hospital, for their help in doing this work.

\section{Authors' contributions}

Both authors equally participated in operating patients, data collection, data analysis, and scientific writing. Both authors read and approved the final manuscript.

\section{Funding}

There was no funding for this study.

\section{Availability of data and materials}

The datasets used and/or analyzed during the current study are available from the corresponding author on reasonable request.

\section{Ethics approval and consent to participate}

Approved from the research ethics committee of Faculty of Medicine at Tanta University [reference number 33038 obtained in April 2019]. Consent for participation was not applicable as this is a retrospective study, so the ethics committee waived the consent to participate.

\section{Consent for publication}

Not applicable.

\section{Competing interests}

The authors declare that they have no competing interests.

Received: 5 July 2019 Accepted: 16 October 2019

Published online: 27 November 2019

\section{References}

1. Terry JC, Michael GF. Surgical management of cervical disc disease and spondylosis. In: Tindall GT, Cooper P, Barrow DL, editors. The Practice of Neurosurgery; Vol. 1, Chapt 158; 1997. p. 2409-22.

2. Wardak Z, Lavelle ED, Lavelle WF. Functional anatomy of the spine. In: Steinmetz MP, Benzel EC, editors. Benzel's spine surgery: techniques, complication avoidance, and management, vol. chap. 5: Elsevier; 2017. p. 43.

3. Aebi M, Arlet V and Weeb JK: AOSPINE Manual Clinical Applications 2007; Vol. 2, chap 7: 545

4. Nelson Moussazadeh and Kai-Ming Gregory Fu: Spinal anatomy, in Youmans and Wenn neurological surgery, 2017: Part I, 273, 3916

5. Hayashi K, Yabuki T, Kurokawa T, Seki H, Hogaki M, Minoura S. The anterior and the posterior longitudinal ligaments of the lower cervical spine. J Anat. 1977;124(Pt 3):633-6.

6. Wiltse LL, Fonseca AS, Amster J, Dimartino P, Ravessoud FA. Relationship of the dura, Hofmann's ligaments, Batson's plexus, and a fibrovascular membrane lying on the posterior surface of the vertebral bodies and attaching to the deep layer of the posterior longitudinal ligament. An anatomical, radiologic, and clinical study. Spine. 1993;18(8):1030-43.

7. Parke WW, Bono CM, and Garfn SR: Applied anatomy of the spine in Rothman-Simeone (ed): the spine, ed.6, Elsevier Saunders, chapter, 2, section 1, p:15-53, 2011

8. Wells-Roth D and Zonenshayn M: Vascular anatomy of the spine, operative techniques in Neurosurgery, Vol 6, No 3 (September): pp 116-121, 2003

9. Williams KA, Jr, Rauschning W, Prasad S: Applied anatomy of the cervical spine In: Steinmetz MP and Benzel EC, editors. Benzel's spine surgery: techniques, complication avoidance, and management. Elsevier 2017; chap. 8, p. 87

10. Girolami M, Ghermandi RM. Gasbarrini GA and Boriani S: Anatomy of the subaxial cervical spine in: Boriani S, et al, Editors. Atlas of craniocervical junction and cervical spine surgery @ Springer International Publishing Switzerland 2017; chapter 6, P: 69

11. Kondziolka DS, Pirris S, Lunsford L. Improving the informed consent process for surgery. Neurosurg. 2006;58(6):1184-9.

12. Saifuddin A, Green $R$, White J. Magnetic resonance imaging of cervical ligaments in the absence of Trauma. Spine. 2003;28(15):1686-92.

13. Vaccaro AR, Falatyn SP, Flanders AE, Balderston RA, Northrup BE, Cotler JM. Magnetic resonance evaluation of the intervertebral disc, spinal ligaments, 
and spinal cord before and after closed traction reduction of cervical spine dislocations. Spine. 1999;24(12):1210-7.

14. Beutler W, Sweeney CMA, Connolly P. Recurrent laryngeal nerve injury with anterior cervical spine surgery: risk with laterality of surgical approach. Spine. 2001;26(12):1337-42.

15. Okada Y, Kawamata T, Kawashima A, Yamaguchi K, Hori T. Pressurecontrolled dual irrigation-suction system for microneurosurgery: technical note. Neurosurgery. 2009;65:E625.

16. Kienapfel H, Koller M, Hinder D, George CH, Pfeiffer M, Klose K, Lorenz W, Griss P. Integrated outcome assessment after anterior cervical discectomy and fusion. Spine. 2004;29(22):2501-9.

17. Takhtani D, Melhem E. MR imaging in cervical spine trauma. Clin Sports Med. 2002;21(1):49-75.

18. Yamazaki A, Homma T, Ishikawa S, Okumura H. Magnetic resonance imaging and histologic study of hypertrophic cervical posterior longitudinal ligament: case report. Spine. 1991;16(11):1262-6.

19. Heary RF, Karimi RJ, Jalan D and Benzel EC: Single- and multiple-level interbody fusion techniques. In: Steinmetz MP and Benzel EC, editors. Benzel's Spine Surgery: Techniques, Complication Avoidance, and Management. Elsevier 2017; chap. 59, p. 519-531

20. Sonntag VKH, Han PP, Vishteh AG. Anterior cervical discectomy. Neurosurgery. 2001;49(4):909-12.

21. Tu TH, Chang CC, Wu JC, Fay LY, Huang WC, Cheng H. Resection of uncovertebral joints and posterior longitudinal ligament for cervical disc arthroplasty. Neurosurg Focus. 2017;42(VideoSuppl1):V2.

22. Cloward R. Anterior cervical discectomy and fusion: the Cloward technique. In: Rengashary, Wilkins, editors. Neurosurgical Operative Atlas, vol. 2. 2nd ed. Chicago: The American Association of Neurological Surgeons; 1992. p. 22940.

23. Shapiro S. Multilevel corpectomy for cervical spondylotic myelopathy. Sem Neurosurg. 2003;14(1):5-13.

24. Charles H, Crawford K III, Riew D. Cervical discectomy. In: Steinmetz MP, Benzel EC, editors. Benzel's spine surgery: techniques, complication avoidance, and management, vol. chap. 71: Elsevier; 2017. p. 608.

25. Meyer SA, Knightly JJ. Evaluation and treatment of cervical disk herniations. Youmans Wenn. 2017;283:4043.

26. Yamazaki S, Kokubun S, Ishii Y, Tanaka Y. Courses of cervical disc herniation causing myelopathy or radiculopathy: an analysis based on computed tomographic discograms. Spine. 2003;28:1171-5.

27. Ohyama S, Takahashi S, Tamai K, Hori Y, Hirakawa Y, Hoshino M, Suzuki A, Nakamura H. Prevention of nerve root thermal injury caused by bipolar cauterization near the nerve roots. Spine. 2019;44:E321-8.

28. Weinstein PR. Anterior cervical discectomy and fusion: Smith-Robinson technique. In: Rengashary, Wilkins, editors. Neurosurgical Operative Atlas, vol. 3. 2nd ed. Chicago: The American Association of Neurological Surgeons; 1993. p. 344-57.

29. Bertalanaffy H, Eggert HR. Complications of anterior cervical discectomy without fusion in 450 consecutive patients. Acta Neurochir. 1989;99:41-50

30. Sang H, Wilson CB. Post-operative epidural hematoma as a complication of anterior cervical discectomy: report of three cases. JNS. 1978;49:288-91.

31. Protzman NM, Kapun J, Wagener CH. Thoracic spinal subdural hematoma complicating anterior cervical discectomy and fusion: case report. Neurosurg Spine. 2016;24:295-9.

32. Lin $W$, Xue $Y$, Zhao $Y$, Zong $Y$, Sun $C$, Pei B, et al. Disc associating axial pain were indicated by PLL resection in ACDF surgery. Eur Spine J. 2017;26(4): 1211-6.

33. Gabriele Molteni, Marco Giuseppe Greco and Pierre Guarino: Complications of cervical spine surgery in Boriani S, et al, (Editors) Atlas of Craniocervical Junction and Cervical Spine Surgery @ Springer International Publishing Switzerland 2017, chapter, 2; PP: 19-24

34. Elayouty AD, Mashaly HA, Sabry HA. Posterior longitudinal ligament resection in anterior cervical discectomy: Egyptian. J Neurosurg. 2019;33:3.

35. Nassr A, Aleem IS, Jason C, Woods B, Ponnappan RK, Donaldson WF, Kang JD. Does resection of the posterior longitudinal ligament impact the incidence of C5 palsy after cervical corpectomy procedures? A Review of 459 Consecutive Cases. Spine. 2017;42:E392-7.

\section{Publisher's Note}

Springer Nature remains neutral with regard to jurisdictional claims in published maps and institutional affiliations.

\section{Submit your manuscript to a SpringerOpen ${ }^{\circ}$ journal and benefit from:}

- Convenient online submission

- Rigorous peer review

- Open access: articles freely available online

High visibility within the field

- Retaining the copyright to your article

Submit your next manuscript at $\boldsymbol{\nabla}$ springeropen.com 